\title{
As veredas do ordenamento jurídico da Educação Infantil do Campo: um olhar sobre os jogos e brincadeiras
}

\author{
Juridical order pathways for infant education in rural areas: a glimpse into \\ playing and games
}

Elizabete Pereira Barbosa

Doutora em Educação

Professora Adjunta do Departamento de Educação da Universidade Estadual de Feira de Santana - UEFS Feira de Santana, Bahia- Brasil. beteuefs@uefs.br

Luciana Freitas de Oliveira Almeida Graduada em Educação Física pela Universidade Estadual de Feira de Santana - UEFS Feira de Santana, Bahia- Brasil. luh_feira@hotmail.com

Resumo: O presente artigo tem como objetivo analisar as contribuições dos jogos e brincadeiras na Educação Infantil do Campo nas escolas municipais dos distritos de Feira de Santana, estado da Bahia. Este trabalho baseia-se em pesquisa empírica e bibliográfica. Os referenciais teóricos estão fundamentados à luz do Coletivo de Autores (1992); Kishimoto (1993; 2007), no ordenamento jurídico (BRASIL, 1988, 1998) e nos documentos oficiais como: Lei de Diretrizes e Bases da Educação no 9.394/96 (BRASIL 1996). A pesquisa revela que os jogos e brincadeiras são trabalhados prioritariamente como estratégia metodológica nas aulas de Educação Física e os professores compreendem a importância do conteúdo para o desenvolvimento integral das crianças.

Palavras-chave: Educação do Campo. Educação Infantil. Jogos e brincadeiras.

Abstract: The present paper aims to analyze the contributions of playing and games in rural childhood education in municipal schools located in the districts of Feira de Santana, State of Bahia. This work is based on empirical and bibliographic research. The theoretical references are based on the studies of the Coletivo de Autores (1992); Kishimoto (1993, 2007), in the juridical order (BRASIL, 1988, 1998) and in official documents such as: Policy of Guidelines and Bases of Education $n^{\circ} 9.394$ / 96 (BRASIL 1996). The research reveals that playing and games are carried out primarily as a methodological strategy in Physical Education classes and teachers understand the importance of this content for the children's integral development.

Keywords: Rural Education. Infant Education. Playing and games. 


\section{Introdução}

O presente trabalho tem como questão de pesquisa compreender quais as contribuições dos jogos e brincadeiras para as crianças da educação Infantil do campo, no município de Feira de Santana, estado da Bahia e como objetivo analisar as contribuições dos jogos e brincadeiras para as crianças do campo.

Trata-se de um estudo inspirado nos princípios do estudo de caso, de abordagem qualitativa. Feira de Santana tem oito distritos, foi selecionado um distrito que se constituiu como lócus da pesquisa e uma escola municipal de educação infantil, com dois professores de Educação Física, que se disponibilizaram a participar da entrevista respeitando todos os procedimentos éticos estabelecidos para a pesquisa científica em Ciências Humanas.

Trata-se de uma temática pouco investigada e sua realização trouxe novas reflexões em torno da Educação Física nas escolas de Educação Infantil do Campo através do levantamento da produção da área em estudo, da revisão de literatura e de dar voz aos sujeitos, no caso as professoras utilizando a entrevista semiestruturada. A realização da pesquisa foi iniciada com um levantamento de produção, num período de dez anos (2010 a 2019) no banco de dados da ANPED (Associação Nacional de Pesquisa e Pós-graduação em Educação), Portal do Ministério de Educação- MEC e na revista Motrivivência, dialogando também com autores que debatem sobre educação do campo, educação infantil, jogos e brincadeiras analisando as principais temáticas, lacunas e tendências da produção acadêmica. Com o levantamento realizado os resultados apontam que, embora as pesquisas sobre Educação do Campo tenham aumentado significativamente nas últimas décadas, o número de trabalhos acerca da Educação Física na Educação Infantil do Campo ainda é exíguo.

Um exemplo ilustrativo foi o resultado da análise da produção dos trabalhos publicados nos dez anos (2010 a 2019) no banco de dados da ANPED. Para melhor selecionar os textos, utilizou-se três palavras-chaves (Educação Infantil, Educação do Campo e Jogos e Brincadeiras). Foram encontrados quarenta e cinco trabalhos com a temática, todos lidos na íntegra, porém, dos quarenta e cinco encontrados, apenas cinco textos dialogam sobre os jogos e brincadeiras no contexto da Educação Infantil; dentre estes cinco textos, apenas dois da mesma autora dialogam com os jogos e brincadeiras na Educação Infantil do Campo.

$\mathrm{Na}$ revista Motrivivência não foi encontrado artigo que trate da Educação Física ou dos jogos e brincadeiras na Educação Infantil do Campo. Para melhor selecionar os textos, utilizou-se quatro palavras-chave (Educação Infantil, Educação do Campo, Educação Física e Jogos e Brincadeiras). Foram encontrados dez trabalhos com a temática, todos lidos na íntegra, porém, dos 
dez encontrados apenas três textos dialogam sobre Educação Física no contexto da Educação Infantil; dois textos dialogam sobre as brincadeiras nas aulas de Educação Física para crianças e um texto discute a formação do profissional de Educação Física para atuar na Educação do Campo, não foi encontrado trabalho que dialogue com a Educação Física ou seu conteúdo, jogos e brincadeiras, na Educação Infantil do Campo, demonstrando que o tema tem sido silenciado.

Fez-se também um levantamento de dados no Portal do MEC (Ministério de Educação) foram encontrados apenas dois trabalhos voltados para a Educação Infantil do Campo. Resgatando a portaria n ${ }^{\circ}$ 6, de 16 de maio de 2013 que Institui Grupo de Trabalho Interinstitucional para a Educação Infantil no Campo e versa sobre a obrigatoriedade constitucional de matrícula/frequência escolar a partir dos 04(quatro) anos de idade. Encontrou-se também uma produção do referido grupo, intitulado "Educação Infantil do Campo: proposta para expansão política", documento que tem como objetivo apresentar proposta e discernimentos para a ampliação da política de educação infantil voltada aos povos do campo. E a outra foi o livro "Oferta e demanda de Educação Infantil do Campo". Na mesma direção, no que tange a Educação Infantil de modo geral o MEC disponibiliza as Diretrizes Curriculares para Educação Infantil, os volumes 1 e 2 dos Parâmetros Nacionais de Qualidade para a Educação Infantil e os Parâmetros Básicos de Infraestrutura para Instituições de Educação Infantil. No que diz respeito aos jogos e brincadeiras, foram encontrados, no portal do MEC, um livro e um documentário intitulado "Território do Brincar", que trazem informações sobre brinquedos e brincadeiras com a finalidade de orientar os professores.

A revisão de literatura através do ordenamento jurídico revela que ter acesso à educação é um direito garantido pela Constituição Federal de 1988, isto está explícito em seu Art. $6^{\circ}$ que determina como direitos sociais “a educação, a saúde, o trabalho, o lazer, a segurança, a previdência social, a proteção à maternidade e à infância, a assistência aos desamparados, na forma desta Constituição" (BRASIL, 1988).

No mesmo sentido a educação básica de acordo com a Lei de Diretrizes e Bases-LDB n ${ }^{\circ}$ 9.394/96 em seu art. 22 (...) tem por finalidade desenvolver o educando, assegurar-lhe a formação comum indispensável para o exercício da cidadania e fornecer-lhe meios para progredir no trabalho e em estudos posteriores(BRASIL, 1996). A educação infantil é a primeira etapa da educação básica e precisa assegurar o desenvolvimento pleno do educando, nesse sentido a mesma lei no art. $29^{\circ}$ determina: 
[...] A educação infantil, primeira etapa da educação básica, tem como finalidade o desenvolvimento integral da criança até seis anos de idade, em seus aspectos físico, psicológico, intelectual e social, complementando a ação da família e da comunidade (BRASIL, 1996).

Considerando o ordenamento jurídico, as ações da escola, família e comunidade são indissociáveis. Nesta mesma lei no parágrafo $3^{\circ}$ do artigo 26 institui que a Educação Física, integrada a proposta pedagógica da escola, é componente curricular obrigatório da educação básica (BRASIL, 1996). Delibera também no Art. 28, a necessidade de adaptações na oferta de educação básica para a população rural. Define de modo exato que os sistemas de ensino promovam as adaptações necessárias à sua adequação às peculiaridades da vida rural e de cada região. O artigo da lei assevera o dever dos estabelecimentos de ensino em assegurar tais adaptações e dispõe que:

I- conteúdos curriculares e metodologias apropriadas às reais necessidades e interesses dos alunos da zona rural;

II- organização escolar própria, incluindo adequação do calendário escolar às fases do ciclo agrícola e às condições climáticas;

III- adequação à natureza do trabalho na zona rural (BRASIL, 1996).

Analisando sintaticamente o artigo, está prescrito em lei que as crianças residentes em áreas rurais têm direito a uma educação com as adaptações indispensáveis para respeitar a diversidade. É preciso considerar que são muitas identidades e muitas infâncias oriundas de famílias da agricultura familiar, da pesca, de quilombos, do extrativismo, de assentamentos é preciso que tenham garantias em relação ao acesso, permanência, alimentação escolar, processo pedagógico que considere as especificidades de cada local. Assim, cada escola deve ser considerada com todas as suas especificidades, enfatizando a importância que seja uma escola rica de sentidos com aulas ministradas despertando nos alunos o prazer e o encanto em aprender.

Entendemos a infância como construção social, que reflete as variações existentes nas relações e nos processos históricos da atividade humana, ou seja, a criança aqui é considerada como um sujeito produtor de relações sociais e que está inserido em um determinado contexto social. A infância para Barbosa (2015) é uma construção histórica e sociocultural em que a idade não é um elemento definidor e, portanto, não consegue explicar sua variabilidade.

As crianças aprendem através das brincadeiras, por meio de imitações e através da representação de papeis aprende a forma que a sociedade está organizada. No que concerne à educação infantil, a criança tem uma visão geral da realidade, as informações aparecem de formas misturadas e complexas para elas, para o Coletivos de Autores (1992) este é o ciclo de organização da identidade dos dados da realidade. Neste caso, cabe à escola, principalmente ao professor orientá-los na sistematização das informações difusas descritas pelos alunos. 
Sabe-se que a escola tem um papel importantíssimo na formação da criança e na educação infantil a criança se apropria dos conhecimentos da humanidade e desenvolve-se progressivamente. Fica claro o desejo da criança em conhecer os fenômenos que as cercam diante de suas manifestações, principalmente, em coisas desconhecidas e a escola é um espaço sociocultural que favorece o contato com esse tipo de saber mais elaborado/sistematizado.

A escola é uma instituição social, cujo papel específico consiste em propiciar o acesso ao conhecimento sistematizado daquilo que a humanidade já produziu e que é necessário às novas gerações para possibilitar que avancem a partir do que já foi construído historicamente (MARSIGLIA, 2011, p. 10).

A educação infantil no meio rural ainda é pouco discutida, muitas vezes é vista de forma precária e na maioria dos casos, de forma isolada e esquecida pela sociedade. Porém, é fato que os alunos que vivem no campo merecem o mesmo respeito daqueles que frequentam as escolas dos centros urbanos.

Se por um lado o itinerário legislativo sobre a educação do campo, educação infantil e a obrigatoriedade da oferta de Educação Física nestes espaços já está previsto em lei desde 1996, por outro, o tema ainda é silenciado e a discussão acadêmica ainda é tímida. Nesse sentido, vale ressaltar os estudos de Mendes; Rodrigues (2015), defendendo a importância dos jogos e das brincadeiras na organização pedagógica na educação infantil do campo.

O brincar para a criança do campo é um momento de lazer precioso e não priorizado, onde se busca no seu brincar a sua realidade vivida, sem brinquedos aparentes ele acaba por criar, usando da sua imaginação em instrumentos retirados do próprio lugar onde vive, como: paus, pedras, folhas e o manuseio do barro molhado tomam forma de animais, bonecos/as, carros de boi, panelas e etc. sendo reconhecido por ele mesmo, e assim ele vive o seu momento de criação e formação do seu saber (MENDES; RODRIGUES, 2015).

Neste sentido, a organização pedagógica da escola precisa levar em consideração o momento da criação, juntamente com a construção do conhecimento, para isso é fundamental que o professor utilize dentro da sala de aula estratégias que favoreçam a aprendizagem. Os jogos e brincadeiras podem ser utilizados como ferramentas dentro da sala de aula, no momento da interação ensino/aprendizagem. A disciplina Educação Física trata, pedagogicamente, no âmbito escolar, do conhecimento da cultura corporal e, as aulas representam uma grande contribuição no desenvolvimento integral da criança conforme prevê a lei.

A Educação Física é uma prática pedagógica que, no âmbito escolar, tematiza formas de atividades expressivas corporais como: jogo, esporte, dança ginástica, formas estas que configuram uma área de conhecimento que podemos chamar de cultura corporal (COLETIVO DE AUTORES, 1992, p. 33). 
Nesse sentido, fica evidente a importância dos jogos e brincadeiras como práticas pedagógicas essenciais para o desenvolvimento da criança e por isso é necessário trazer à baila da discussão que, nas escolas esta prática é colocada como algo secundário.

O brincar é um dos tópicos presentes no Referencial Curricular Nacional para a Educação Infantil- RCNEI (BRASIL, 1998). O documento defende que é a partir do brincar que a criança irá desenvolver a sua identidade e sua autonomia. Uma das brincadeiras apontadas pelo RCNEI é o faz-de-contas, onde, a partir dele a criança irá representar papéis sociais, estabelecer interação com outras crianças, e consequentemente reconhecer o seu eu enquanto sujeito gestor das ações e reações de sua imaginação.

\footnotetext{
Brincar constitui-se, dessa forma, em uma atividade interna das crianças, baseada no desenvolvimento da imaginação e na interpretação da realidade, sem ser ilusão ou mentira. Também tornam-se autoras de seus papéis, escolhendo, elaborando e colocando em prática suas fantasias e conhecimentos, sem a intervenção direta do adulto, podendo pensar e solucionar problemas de forma livre das pressões situacionais da realidade imediata (BRASIL, 1998, p.23).
}

Ainda segundo o RCNEI, o brincar é um ato que se desenvolve no campo da imaginação, ou seja, a criança que brinca é preciso que conte com o domínio da linguagem simbólica. Diante disso, nas brincadeiras de representações de papéis ou de faz-de-contas, é preciso haver uma consciência da criança na diferença existente entre a brincadeira e a realidade imediata que o concedeu conteúdo para realizar/representar tal brincadeira de sua imaginação. Neste universo de estudos, o texto está organizado em duas partes. Na primeira parte dialoga com os documentos oficiais nacionais e, na segunda parte enfatiza as contribuições dos jogos e brincadeiras para a Educação Infantil do Campo.

As veredas dos jogos e brincadeiras nas escolas de Educação Infantil do campo em Feira de Santana

A educação infantil é a primeira etapa da educação básica e a legislação preconiza que a Educação Física é componente curricular obrigatório da educação básica. Porém, no município de Feira de Santana o profissional licenciado em Educação Física não é recrutado para esta etapa da educação. Nesse sentido, a escola em estudo dispõe de dois estagiários que cumprem carga horária substituindo os professores efetivos das classes de educação infantil quando estes estão no momento destinado à atividade complementar. Regulamentada através da portaria 09/2017 a reserva de carga horária para atividade complementar, no município de Feira de Santana destina um terço do tempo de trabalho docente para atividades complementares e no art. $1^{\circ}$ fica definido que: 
[...] o horário de Atividade Complementar é destinada a planejamento, avaliação, estudos, reuniões pedagógicas, reuniões de pais e/ou responsável legal, se necessário, atualização do sistema digital, formação continuada do professor e acompanhamento pedagógico da escola (FEIRA DE SANTANA, 2017).

Ao pensar sobre o lugar que os jogos e brincadeiras ocupam dentro da Educação Infantil do Campo, cabe retomar alguns dispositivos legais como a LDB 9.394/96 que estabelece no Art. 28, a necessidade de adaptações na oferta de educação básica para a população rural, considerando os conteúdos, metodologias, organização escolar própria, adequação do calendário e a organização do trabalho pedagógico à natureza do trabalho na zona rural. No caso investigado não há qualquer tipo de alteração no calendário escolar para atender as especificidades do espaço rural. Fica evidente que ainda não há uma política municipal de atenção às especificidades da educação para os indivíduos do campo, em particular, as crianças. É importante salientar que a Educação Infantil do Campo deve ser considerada com todas as suas particularidades, ressaltando a importância da permanência na escola e as aulas precisam envolver as crianças com o prazer e o encanto em aprender.

Nesse sentido, se no artigo 29, da mesma Lei 9.394/96 fica estabelecido que a Educação Infantil, tem como finalidade o desenvolvimento integral da criança, em seus aspectos físico, psicológico, intelectual e social, complementando a ação da família e da comunidade (BRASIL, 1996) é necessário pensar políticas locais para contribuir com tal desenvolvimento.

Os dois estagiários da escola dispõem de um tempo insuficiente para cumprir o que está determinado na LDB 9394/96, no parágrafo $3^{\circ}$, do artigo 26 quando institui que a Educação Física, integrada a proposta pedagógica da escola, é componente curricular obrigatório da educação básica (BRASIL, 1996). Mesmo analisando os impactos da ausência de políticas municipal de atenção ao que determina o ordenamento jurídico nacional ficou evidente o esforço do professor A, quando afirmou que desenvolve muitas atividades que estimulam o desenvolvimento motor e psicológico da criança, assim contribuindo para aumentar as habilidades motoras. Ressaltou que utiliza tanto as atividades de recreação quanto atividades elaboradas, entretanto não especificou a diferença entre atividade elaborada e de recreação.

Já o professor B, desenvolve seu trabalho na escola com as crianças do grupo 5 e afirma que trabalha com jogos interativos. Embora não especifique quais são os jogos ele deixa claro que tais atividades desenvolvem o raciocínio da criança, explicou que trabalha com brincadeiras com a intencionalidade de desenvolver o raciocínio lógico. Toda sua fala deixou evidente uma preocupação com o desenvolvimento cognitivo da criança

O jogo é entendido como fator de desenvolvimento, onde a criança age através do que significa suas ações, fazendo desenvolver a vontade como também suas escolhas e decisões. 
o jogo satisfaz necessidades das crianças, especialmente a necessidade de "ação". Para entender o avanço da criança no seu desenvolvimento, o professor deve conhecer quais motivações, tendências e incentivos que a colocaram em ação. Não sendo o jogo aspecto dominante da infância, ele deve ser entendido como "fator de desenvolvimento" por estimular a criança no exercício do pensamento, que pode desvincular-se das situações reais e leva-la a agir independentemente do que ela vê (COLETIVO DE AUTORES 1992, p.65).

Percebe-se nas falas dos professores A e B que utilizam estratégias metodológicas diferentes, um desenvolve mais suas aulas voltadas para a questão motora, já o outro voltado mais para questão da interatividade com ênfase no desenvolvimento cognitivo, utilizando-se dos jogos e brincadeiras.

Em relação à organização do trabalho pedagógico o docente A, utiliza uma fala imprecisa, mas reafirma que organiza de diferentes formas o ambiente educacional priorizando desenvolvimento motor e o equilíbrio. O referido professor tem uma experiência de um ano e meio na Educação Infantil e afirmou que está vivenciando a primeira experiência com educação do campo. Já o professor B, estabelece que além das atividades diárias, desenvolve projetos na escola voltados para a valorização do distrito. Não se trata apenas do conteúdo específico da Educação Física, mas a valorização da identidade das crianças do campo e citou um projeto envolvendo a organização de uma horta escolar. Com apenas um ano de experiência em educação, o professor B, desenvolve um trabalho importante para que as crianças do campo tenham o pertencimento com a escola, no espaço geográfico no qual estão inseridas. Nesse sentido, tanto o professor A quanto o B ainda não acumularam experiência na educação do Campo, situação perfeitamente compreensível, pois ambos ainda estão em formação inicial tendo sido contratados pelo poder público municipal para realizar estágio e não para assumir as atividades de um professor regente.

É importante ressaltar que mesmo com pouca experiência, os professores reforçam que trabalham com jogos e brincadeiras em sala de aula porque contribuem para o desenvolvimento das crianças. Assim, o professor A em sua fala defende que além de contribuir para o desenvolvimento global da criança, ajuda no processo de socialização e se torna um aliado no trabalho com as crianças que apresentam desatenção extrema ou um comportamento impulsivo. Já o professor B, afirma que antes de iniciar a aula apresenta o conteúdo, mostra aos alunos os procedimentos, esclarecendo o objetivo da brincadeira, defende a necessidade do aluno entender o que está fazendo e o propósito daquela aula. Vale destacar que esta atitude faz toda diferença para o bom desenvolvimento da atividade sendo um importante elemento na organização do trabalho pedagógico e o professor utiliza o substantivo brincadeira como sinônimo do conceito de jogo. Darido e Rangel (2005) e o Coletivo de Autores (1992) compartilham da mesma ideia, que 
os jogos e brincadeiras são vistos como sinônimos compreendidos indistintamente. O jogo possui uma liberdade de ação e invenção, o que parece ser difícil, torna-se fácil através do jogo. Defendem que os jogos e brincadeiras são essenciais para o desenvolvimento da criança e embora o professor B ressalte que ao trabalhar com jogos e brincadeiras é necessário um cuidado, pois cada região tem seus costumes. Defende que a escola trabalhe no sentido de fortalecer a cultura regional onde está inserida, sem negar aos alunos as outras formas de brincar. Porém, nada foi mencionado em torno do como fazer tais adequações dos jogos às peculiaridades locais. Não se trata apenas de realizar a atividade, mas de desenvolver o raciocínio lógico, autonomia, criticidade, criatividade, responsabilidade, interação, cooperação e o reconhecimento do lugar onde estão inseridos.

É sabido que a cada região as brincadeiras variam de nomes ou de algumas regras, mas não perde seu sentido, sua essência continua a mesma. Para ilustrar, Darido e Junior (2015) apresentam um exemplo que o mesmo jogo que é jogado em São Paulo com o nome de queimada; é jogado em Salvador com o nome de baleado. Já para Kishimoto(2007) o jogo assume a imagem, o sentido que cada sociedade lhe atribui. É este aspecto que nos mostra porque, dependendo do lugar e da época, os jogos assumem significações distintas.

Os jogos tradicionais infantis são expressões culturais acumuladas ao longo da vida humana, são transmitidos pela oralidade e por esse fato há uma dificuldade em saber ao certo sua origem. As características que definem os jogos tradicionais são a tradicionalidade, transmissão oral e universalidade. Os jogos populares também apresentam essas mesmas características, ou seja, os jogos tradicionais também conhecidos como jogos populares são considerados como patrimônios culturais da humanidade.

De acordo com Kishimoto(1993) o jogo assume características de anonimato, tradicionalidade, transmissão oral, preservação, mudança e universalidade. É considerado como parte da cultura popular, que por sua vez, carrega consigo a criação de um povo em um determinado período histórico. Porém, o jogo não fica paralisado no tempo, pois, por ser passada adiante pela oralidade é transmitida para as próximas gerações, em um processo de transformação constante. Kishimoto(1993) afirma que a origem do jogo é desconhecida e seus criadores são uma incógnita, apenas os únicos fatos que se sabem, é que o jogo é proveniente das práticas deixadas pelos adultos, indícios do período do romantismo, poesia, mitos e rituais religiosos.

O jogo é considerado um conteúdo universal, pelo fato de que os mesmos jogos que eram brincados na antiguidade continuam nos dias atuais quase que da mesma forma, sem perder sua essência com o passar do tempo. Ainda segundo Kishimoto (1993) a força de tais jogos explicase pelo poder da expressão oral. São manifestados de forma espontânea, conhecidos da cultura 
popular, os jogos levam consigo o objetivo de perpetuar a cultura infantil e estabelecer formas de coexistência coletiva. O jogo é visto como não material, possui uma realidade autônoma, não está ligado a qualquer grau determinado de civilização pelo fato de não haver uma data que sua inicie a origem, porém, é impossível negar a existência do jogo. Ele é uma atividade voluntária, altruísta, há uma liberdade pura na relação do jogo, é possível, em qualquer momento, adiar ou suspender o jogo.

Além disso, os jogos populares também são conhecidos como jogos regionais ou tradicionais. No entanto, é realizado com maior frequência pelas crianças das classes populares. Apresentam-se como uma relevante forma de manifestação lúdica, sendo praticados em diversos lugares sem que haja a necessidade de muitos materiais para acontecer. O conhecimento sobre os jogos são passados de geração para geração, sendo uma forma de estabelecer um elo entre as várias culturas existentes e presenciar de forma vívida a memória das gerações anteriores (BARBOSA; ALMEIDA, 2019).

Diante disto, é possível identificar através dos jogos e brincadeiras que as crianças aprendem sobre um saber popular, transmissor de cultura e, mediante isso, conhecer como viviam a sociedade em determinadas épocas. Desta forma, os jogos e brincadeiras na infância possibilitam a construção de uma variedade de conhecimentos históricos das manifestações culturais, ludicidade, cooperação elementos essenciais para o desenvolvimento global da criança esteja ela na educação do campo ou nos grandes centros urbanos.

\section{Considerações finais}

Ao pesquisar as contribuições dos jogos e brincadeiras na Educação Infantil do campo ficou evidente que o tema ainda é pouco investigado, pois a produção na literatura sobre a temática é limitada e há necessidade de novos estudos e novas questões de pesquisa, sobretudo em torno da presença do professor de Educação Física no ambiente escolar supracitado.

Os estudos revelaram que os jogos e brincadeiras nas aulas da Educação Infantil do Campo contribuem para o desenvolvimento, aprendizagem, valorização dos saberes e culturas das crianças campesinas.

Por outro lado, no lócus da pesquisa o trabalho é desenvolvido por estagiários, em formação inicial no curso de licenciatura em Educação Física, sem experiência, que ocupa apenas a reserva de carga horária de acordo com a Portaria 09/2017 de Feira de Santana, uma carga horária muito limitada. Para fazer um trabalho significativo com os jogos e brincadeiras é necessário garantir que a Educação Física tenha garantia de carga horária em cumprimento ao que prevê a 
LBD 9.394/96 quando garante que a Educação Física, integrada a proposta pedagógica da escola, é componente curricular obrigatório da educação básica, e a educação infantil faz parte da educação básica.

Vale destacar também que a referida escola não dispõe de um calendário escolar próprio que respeite as especificidades do meio rural, conforme estabelece a LDB 9.394/96 e os alunos faltam aulas nos períodos de plantio/colheita para acompanhar a família durante o ciclo agrícola tanto para aprenderem quanto para ajudarem no processo.

$\mathrm{Na}$ escola pesquisada os jogos e brincadeiras são trabalhados como estratégia metodológica e como conteúdo de formas sistemáticas e os professores compreendem a importância do conteúdo para o desenvolvimento integral da criança.

Nesse sentido, o estudo evidenciou a importância dos jogos e brincadeira na educação infantil de forma regular e sistemática, sabendo que o mesmo desenvolve na criança habilidades de raciocínio rápido, autonomia, criticidade, criatividade, responsabilidade e cooperação. Tal estratégia possibilita que as crianças se desenvolvam através das relações que irão estabelecer com os diferentes objetos, ambientes e sujeitos ali presentes.

Portanto, os jogos e brincadeiras contribuem de maneira significativa para o desenvolvimento da criança, da sua inserção na vida social, transmitem cultura, história, desenvolvem habilidades motoras complexas, identidade, autonomia, não exigem espaço ou material aprimorados e podem ser praticados em qualquer faixa etária. O brincar é um ato que se desenvolve no campo da imaginação, ou seja, colabora para que a criança se reconheça enquanto autor de suas ações e reações pertinentes de sua linguagem simbólica.

\section{Referências}

BARBOSA, Elizabete P. A Fábrica, a Casa e a Escola: As Políticas de Educaşão para a Infância no Recôncavo Fumageiro da Babia (1925 -1946). Tese (Doutorado em Educação) - Universidade Federal da Bahia. Salvador, p. 228. 2015. Disponível em: https://repositorio.ufba.br/ri/handle/ri/18531. Acesso em: 16 de junho de 2020.

BARBOSA, Elizabete P.; ALMEIDA, Luciana F. de O. O trabalho pedagógico com jogos e brincadeiras na educação infantil do Campo. In: SOUSA, Ivan Vale de (org.) Letras, Linguística e Artes: Perspectivas Críticas e Teóricas; v. 2; [recurso eletrônico]. Ponta Grossa (PR): Atena Editora, 2019.

BRASIL. Referencial Curricular Nacional da Educação Infantil. Secretaria de Educação. Brasília: MEC/SEF, 1998. 
BRASIL. Lei Darcy Ribeiro. LDB: Diretrizes e Bases da Educaşão Nacional: Lei 9.394/1996 e legislação correlata. Brasília, DF: Câmara dos Deputados. 2018. Disponível em: http://www.planalto.gov.br/ccivil_03/leis/L9394.htm. Acesso em 24 set. de 2018.

BRASIL. Constituição Federal de 1988. Disponível em: http://www2.camara.leg.br/legin/fed/consti/1988/constituicao-1988-5-outubro-1988-322142publicacaooriginal-1-pl.html. Acessado em 22 de Outubro de 2018.

COLETIVO DE AUTORES. Metodologia do Ensino de Educação Física. São Paulo: Cortez, 1992.

DARIDO, Suraya. C.; JUNIOR, Osmar. M. S. Para ensinar Educação Física: possibilidades de intervenção na escola. Campinas. SP: Papirus. 2015.

DARIDO, Suraya. C.; RANGEL, Irene. C. A. Educação Física na Escola: Implicações para a prática pedagógica. São Paulo. Guanabara Koogan, 2005.

FEIRA DE SANTANA. A SECRETARIA MUNICIPAL DE EDUCAÇÃO DE FEIRA DE SANTANA. Portaria 09/2017. Feira de Santana, 24 de Abril de 2017. Disponível em: http://www.feiradesantana.ba.gov.br/seduc/arq/portaria032016.pdf. Acesso em: 17 de dez. de 2017.

KISHIMOTO, Tizuko. M. Jogos tradicionais infantis: o jogo, a criança e a educação. Petropólis, RJ: Vozes, 1993.

KISHIMOTO, Tizuko. M. Jogo, brinquedo, brincadeira e educação. 10-ed. São Paulo: Cortez, 2007.

MARSIGLIA, Ana Carolina G. A prática pedagógica histórico-crítica na educação infantil e ensino fundamental. Campinas- SP: Autores Associados (Coleção Educação Contemporânea), 2011.

MENDES, Magda B; RODRIGUES, Raquel S. N. A educação no campo multisseriada: descobrindo o prazer do aprender nos jogos, brinquedos e brincadeiras. II Conedu- Congresso Nacional de Educação. 2015.

Recebido em: 17 jun. 2020/ Aprovado em: 13 nov. 2020

Cite como

(ABNT NBR 6023:2018)

BARBOSA, Elizabete Pereira; ALMEIDA, Luciana Freitas de Oliveira. As veredas do ordenamento jurídico da Educação Infantil do Campo: um olhar sobre os jogos e brincadeiras. Dialogia, São Paulo, n. 36, p. 458-469, set./dez. 2020. Disponível em: https://doi.org/10.5585/dialogia.n36.17461.

\section{American Psychological Association (APA)}

Barbosa, E. P., Almeida, L. F. O. (2020, set./dez.). As veredas do ordenamento jurídico da Educação Infantil do Campo: um olhar sobre os jogos e brincadeiras. Dialogia, São Paulo, 36, p. 458-469.

https://doi.org/10.5585/dialogia.n36.17461. 